\title{
A Neural Dissociation Within Language: Evidence that the Mental Dictionary is Part of Declarative Memory, and that Grammatical Rules are Processed by the Procedural System
}

\section{Citation}

Ullman, Michael T., Suzanne Corkin, Marie Coppola, Gregory Hickok, John H. Growdon, Walter J. Koroshetz, and Steven Pinker. 1997. A neural dissociation within language: Evidence that the mental dictionary is part of declarative memory, and that grammatical rules are processed by the procedural system. Journal of Cognitive Neuroscience 9(2): 266-276.

\section{Published Version}

doi:10.1162/jocn.1997.9.2.266

\section{Permanent link}

http://nrs.harvard.edu/urn-3:HUL.InstRepos:3600798

\section{Terms of Use}

This article was downloaded from Harvard University's DASH repository, and is made available under the terms and conditions applicable to Other Posted Material, as set forth at http:// nrs.harvard.edu/urn-3:HUL.InstRepos:dash.current.terms-of-use\#LAA

\section{Share Your Story}

The Harvard community has made this article openly available.

Please share how this access benefits you. Submit a story. 


\title{
A Neural Dissociation within Language: \\ Evidence that the Mental Dictionary Is Part of Declarative Memory, and that Grammatical Rules Are Processed by the Procedural System
}

\author{
Michael T. Ullman \\ Institute for Cognitive and Computational Science \\ Georgetown University \\ Suzanne Corkin \\ MIT
}

Marie Coppola

University of Rochester

Gregory Hickok

University of California, Irvine

John H. Growdon and Walter J. Koroshetz

Massachusetts General Hospital

Steven Pinker

MIT

\begin{abstract}
Language comprises a lexicon for storing words and a grammar for generating rule-governed forms. Evidence is presented that the lexicon is part of a temporal-parietal/medial-temporal "declarative memory" system and that grammatical rules are processed by a frontal/basal-ganglia "procedural" system. Patients produced past tenses of regular and novel verbs (looked and plagged), which require an -ed-suffixation rule, and irregular verbs (dug), which are retrieved from memory. Word-finding difficulties in posterior aphasia, and the general declarative
\end{abstract}

memory impairment in Alzheimer's disease, led to more errors with irregular than regular and novel verbs. Grammatical difficulties in anterior aphasia, and the general impairment of procedures in Parkinson's disease, led to the opposite pattern. In contrast to the Parkinson's patients, who showed suppressed motor activity and rule use, Huntington's disease patients showed excess motor activity and rule use, underscoring a role for the basal ganglia in grammatical processing.

\section{INTRODUCTION}

Two capacities give human language its vast expressive power. One is a "mental lexicon" containing thousands of words, each a memorized, arbitrary sound-meaning pairing. The other is a "mental grammar" of generative rules that combine words into an infinite number of larger words, phrases, and sentences (Chomsky, 1965; De Saussure, 1959; Pinker, 1994). Previous evidence has suggested links between grammatical processing and left

frontal cortex, including Broca's area, and links between lexical memory and left temporal and parietal cortex (Geschwind, 1965; Goodglass, 1993; Wernicke, 1874). The speech of aphasics with frontal (anterior) lesions is often "agrammatic," with a breakdown of sentence structure and the omission or misuse of grammatical morphemes, while access to content words such as verbs and nouns is Iess dramatically impaired (Damasio, 1992; Goodglass, 1993). Electrophysiological and functional neuroimaging studies have also implicated frontal regions in grammati- 
cal processing (Kluender \& Kutas, 1993; Neville et al., 1991; Stromswold et al., 1996). Aphasics with temporal or parietal (posterior) lesions often speak in relatively intact sentence structures, but have severely impaired access to content words (Damasio, 1992; Goodglass, 1993). The dissociation, however, is imperfect and still controversial (Bates \& Wulfeck, 1989; Goodglass, 1993). Most groups of aphasics tested have complex lesion patterns, making symptom-lesion correlations imperfect. Moreover, testing the dissociation has been problematic because tasks probing for grammar and for memory have differed in ways other than their use of the two capacities. In this study we confirm the dissociation using a simple language task in which the use of the two linguistic capacities is contrasted while other factors, such as complexity, meaning and task demands, are held constant.

We also relate the dissociation to larger principles of neural organization. Cutting across the division of the brain into systems such as language and visual perception, there is an orthogonal division into two major kinds of memory systems (Cohen \& Squire, 1980; Mishkin et al., 1984; Damasio \& Damasio, 1992; Squire et al., 1993). One is a declarative memory system underlying the learning and storage of information about facts and events. It is subserved by a medial temporal circuit connected largely with neocortical areas in the temporal and parietal lobes, with the medial temporal components consolidating menories that are eventually stored in neocortex (Cohen \& Squire, 1980; Mishkin et al., 1984; Squire et al., 1993; Suzuki \& Amaral, 1994). The other is a procedural memory system for the learning and processing of motor, perceptual, and cognitive skills. It is subserved by basal ganglia circuits connected largely with frontal cortex (Cohen \& Squire, 1980; Gabrieli et al., 1993; Heindel et al., 1989; Mishkin et al., 1984; SaintCyr et al., 1988; Squire et al., 1993). These parallel basal ganglia circuits are functionally segregated; each receives projections from particular ipsilateral cortical and subcortical areas, and projects via the thalamus to a particular ipsilateral frontal lobe area. Thus a "motor circuit" projects to frontal motor areas, while other circuits project to other frontal areas. The different circuits have similar synaptic organizations within the basal ganglia (Middleton \& Strick, 1994; Alexander et al., 1990; Young \& Penney, 1993).

Given that word forms are like facts in being arbitrary, and in possibly having storage sites in temporal and parietal regions, the temporal-parietal/medial-temporal declarative memory system may subserve words as well as facts and events. Given that rules are like skills in requiring the coordination of procedures in real time, and in possibly having neural loci in frontal regions, the frontal/basal-ganglia procedural system may process grammatical rules as well as motor and perceptual skills. Basal ganglia circuitry may project to Broca's area (Hoover \& Strick, 1993; Preuss, 1995), raising the possibility that portions of the basal ganglia subserve gram- matical processing (Lieberman et al., 1992), performing operations comparable to those done for motor programming. Damasio and Damasio (1992), noting the anatomical interconnections between cortical language areas and the basal ganglia, predict that "the basal ganglia serve to assemble the components of complex motions into a smooth whole, and it seems reasonable that they might perform an analogous function in assembling word-forms into sentences."

We tested this memory/rule dissociation by devising a task based on a simple linguistic system in which reliance on grammar and lexicon differs, while other factors are held constant. Regular (look-looked) and irregular (dig-dug) past tense forms of verbs are wellmatched in complexity (one word), syntax (tensed), and meaning (past). But regular verbs are predictable in form (verb stem $+e d$ ), and new ones are constantly being added (faxed, moshed), whereas irregular verbs are unpredictable (compare sing-sang, fling-flung, bringbrougbt), and constitute a fixed list. A simple theory is that irregular forms are memorized, and regular forms are generated by a rule. The rule comprises two operations: copying the stem, and adding a suffix. Regulars and irregulars interact as follows: Retrieval of an irregular blocks the rule (dug preempts digged); when an irregular is not successfully retrieved, the rule may be applied, resulting in "overregularization" errors such as digged.

Alternative theories have been proposed. In one, regulars and irregulars are both computed by rules (Chomsky \& Halle, 1968; Halle \& Mohanon, 1985), with memory compressed to the minimum information necessary. In another, regulars and irregulars are both computed by a connectionist associative memory, with all rules eliminated (Rumelhart \& McClelland, 1986; MacWhinney \& Leinbach, 1991). Recent evidence from the structure, processing, and acquisition of several languages has bolstered the memory/rule theory (Marcus et al., 1992; Marcus et al., 1995; Pinker, 1991; Pinker \& Prince, 1988; Prasada \& Pinker, 1993), although controversy persists, with some arguing that either an associative memory, or a set of rules, suffices (Hare \& Elman, 1995; Ling \& Marinov, 1993; Plunkett \& Marchman, 1993). It is therefore important to confirm the memory/rule distinction in the form of a neural dissociation, and to use it to illuminate the functions of the major brain systems underlying language and their relation to overall brain organization.

If indeed (a) irregulars are stored words, (b) the temporal-parietal/medial-temporal declarative system underlies word memory, (c) regulars are rule-products, and (d) the frontal/basal-ganglia procedural system underlies the processing of rules, then the following double dissociations are predicted. Patients with impairments of lexical memory, or more generally, of declarative memory, from damage to temporal or parietal neocortex, should be worse at producing irregular past tense forms (dug) than regular ones (looked). They should also make "overregu- 
larization" errors where the irregular fails to be recalled and the rule is applied instead (digged). Finally, they should be able to apply the rule to novel verbs (plagged). In contrast, patients with impairments of rules, or of procedures in general, from damage to frontal cortex or the basal ganglia, should be worse at producing regular than irregular forms. They should not overregularize. And they should be unable to apply the rule to novel verbs. In practice, these differences might be relative rather than absolute, because in a single patient a lesion could strike only a part of a brain system, both brain systems, or a brain system common to the three verb types.

Patients and control subjects read aloud randomly ordered sentence pairs, filling in the blank, such as: "Every day I dig a hole. Just like every day, yesterday I a hole." Twenty sentence pairs contained irregular verbs, 20 contained regular verbs, and 20 contained novel verbs (Table 1). To measure lexical memory, we asked subjects to name 84 drawings of objects (Goodglass et al., 1983). To estimate the severity of any dementia, we gave them the Information, Memory and
Concentration (IMC) subtest of the Blessed Dementia Scale (Blessed et al., 1968). Memory for facts and events was measured by the remote memory subsection of the IMC.

\section{IMPAIRMENTS OF LEXICAL MEMORY}

Alzheimer's Disease (AD) causes severe impairments in learning new, and remembering old, facts, events and words (Corkin, 1982; Nebes, 1989; Sagar et al., 1988), with relative sparing of the learning and processing of motor, perceptual, and cognitive skills (Beatty et al., 1994; Gabrieli et al., 1993; Heindel et al., 1989; Saint-Cyr et al., 1988). A majority of studies find $\mathrm{AD}$ patients relatively unimpaired at processing the syntax of sentences, suggesting that grammar is largely unaffected (Irigaray, 1973; Nebes, 1989; Schwartz et al., 1979). These dissociations may stem from the high densities of neurofibrillary tangles in medial and high-order temporal and temporoparietal regions, and low densities in the basal ganglia and in frontal cortical regions, including Broca's area (Arnold et al., 1991; Kemper, 1994).

Table 1. Stimuli

\begin{tabular}{|c|c|c|}
\hline Task & Word Type & Stimuli \\
\hline \multirow[t]{3}{*}{ Main } & Irregular & $\begin{array}{l}\text { "swam, "dug, "swung, "clung, "wrung, "bent, "bit, "fed, came, made } \\
\text { gave, thought, stood, "kept, " } \text { "drove, "sent, ground, hit, slit, split }\end{array}$ \\
\hline & Regular & 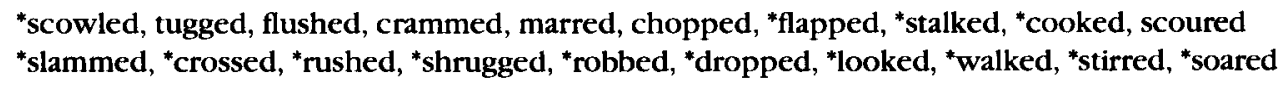 \\
\hline & Novel & $\begin{array}{l}\text { spuffed, traffed, dotched, stoffed, cugged, slubbed, trabbed, pobbed, plagged, crogged } \\
\text { vasked, prassed, bropped, prapped, satched, grushed, plammed, tunched, scurred, scashed }\end{array}$ \\
\hline \multirow[t]{3}{*}{ PD Retest } & Irregular & $\begin{array}{l}\text { sent, spent, lent, }{ }^{*} \text { lost, dealt, felt, meant, kept, }{ }^{*} \text { slept, }{ }^{*} \text { sold } \\
\text { told, "bound, found, held, heard, made, }{ }^{*} \text { rode, wrote, " ate, built, left }\end{array}$ \\
\hline & Regular & $\begin{array}{l}\text { gained, planned, dined, " passed, sailed, failed, joined, stopped, *slipped, "rolled } \\
\text { called, "frowned, owned, pulled, stirred, played, "showed, tried, "stayed, ruled, lived }\end{array}$ \\
\hline & Uninflected & $\begin{array}{l}\text { saint, brand, grind, fast, shield, yield, faint, apt, script, mold } \\
\text { cold, mound, fond, build, bird, aid, code, pride, shade, fold, gift }\end{array}$ \\
\hline \multirow[t]{2}{*}{ AA Reading } & Irregular & $\begin{array}{l}\text { fled, strode, clung, slid, swept, swore, lent, hid, drove, spent } \\
\text { sent, bought, spoke, held, left, kept, felt }\end{array}$ \\
\hline & Regular & $\begin{array}{l}\text { sighed, weighed, slowed, tied, slipped, owed, flowed, viewed, died, loved } \\
\text { learned, stayed, prayed, tried, showed, used, seemed }\end{array}$ \\
\hline
\end{tabular}

Main past tense production task: One sentence was printed one per page. Subjects who misread a verb were asked to restart. If reading was laborious, sentences were read by the experimenters. Responses were transcribed during testing, and when unclear, from audiotape, with careful attention to final consonants of all words, inflected and uninflected. Remaining unclear cases were decided by blind judges. An item was counted as correct if it elicited only correct responses (i.e., if a subject produced both correct and incorrect forms, the item was counted as incorrect). Four irregular items were excluded from the analysis: grind, because ground is a distinct word; and bit, split, slit, because their stems and pasts are identical. Regular and novel verbs did not rhyme with the stem of any irregular verb. Frequencies were taken from Francis and Kucera (Francis and Kucera, 1982), augmented by 1, and ln-transformed. Mean past-tense frequencies: irregular $=3.74$, regular = 2.02. Frequency-matched subsets of regular and irregular verbs were chosen by eliminating the five most frequent irregulars and the six least frequent regulars: mean In past-tense frequency of the remaining 11 irregulars was 2.77 ; of the remaining 14 regulars, 2.70 . These verbs are marked by an asterisk in the table. All subjects were also tested on 60 other verbs, not analyzed here: 20 with regular and irregular forms (divedove/dived), 20 regulars that rhymed with irregulars (glide, cf. bide), and 20 novel words that rhymed with irregulars (strink, cf. stink).

Retest of the hypokinetic PD subjects: Mean In-transformed frequency of the past tense of the irregular verbs was 4.05 ; of the regular verbs, 3.51; of the uninflected forms, 3.34. The subset of six pairs of verbs was selected so that the regular members had slightly bigher mean In past-tense frequency (1.54) than the irregular members (1.38). These verbs are marked by an asterisk in the table.

Reading task for the Anterior Aphasics (AA): Mean In past-tense frequencies of the irregulars was 3.58, of the regulars, 3.42. 
The predictions about dissociations between regular, irregular, and novel forms do not apply to $\mathrm{AD}$ patients across the board; they apply only to patients with severe memory deficits, as manifested in word-finding difficulties. Therefore the predictions may be tested in two ways. One test examines a correlation across an entire group of patients: the greater the word-finding difficulty, the greater the predicted difficulty inflecting irregular verbs (though not regular or novel verbs). The second test focuses on the subset of patients with the most marked word-finding deficits. They should have greater difficulty inflecting irregular than regular or novel verbs, and should make overregularization errors.

We tested 24 probable $A D$ patients and 14 age- and education-matched control subjects (Table 2). Across the $\mathrm{AD}$ patients, difficulties remembering words correlated with difficulties remembering facts $(r(22)=-.61, p<$ .001 ; all reported $p s$ for $r s$ and $t s$ in this paper are one-tailed). As predicted, each of these measures correlated positively with difficulties inflecting irregulars, and correlated negatively with overregularization rates. They did not correlate with difficulties inflecting regular or novel verbs. This pattern held even when IMC dementia scores were partialed out (Table 4).

In the second test, the five patients with the greatest difficulty in remembering words (i.e., the most anomic patients, Tables 2 and 3) were selected. As predicted, they inflected irregular verbs (greatest demand on memory) less reliably than regular verbs. In an Analysis of Variance, the interaction between Irregular/Regular Verb and AD/Control yielded $F(1,17)=20.45, p<.005$; with IMC dementia scores covaried out, $F(1,16)=14.14, p<.005$. In a comparison of the anomic AD patients' performance on regular versus irregular verbs, with subjects as the error term, $t(4)=3.10, p=.018$; with items as the error term, $t(34)=4.86, p<.001$. The anomic $\mathrm{AD}$ patients also inflected irregular verbs less reliably than novel verbs (no demands on memory). For the four anomic AD subjects able to learn novel verbs, the interaction between Irregular/Novel Verb and $\mathrm{AD} / \mathrm{Control}$ yielded $F(1,16)=7.22, p=.016$; with IMC covaried out, $F(1,15)$ $=11.72, p<.005$. In a comparison of the anomic $\mathrm{AD}$ patients' performance on irregular versus novel verbs, with subjects as the error term, $t(7)=2.15, p=.035$; with items as the error term, $t(34)=2.80, p<.005$. The five anomic $\mathrm{AD}$ patients also produced more overregularizations (range $13-44 \%$ of responses, $29-86 \%$ of errors) than their controls, $t(17)=6.45, p<.005$. A similar pattern has been documented in a nongrammatical domain: AD patients can be more impaired pronouncing or writing irregularly spelled words like yacht and pint, which depend on memory, than regularly spelled words like mint and novel ones like rint, which depend on rules (Balota \& Ferraro, 1993; Schwartz et al., 1979; Warrington, 1975).

Posterior Aphasia is associated with word-finding deficits, particularly with content words such as verbs and nouns, in the absence of salient impairments in the articulation and syntactic structure of speech. It generally occurs with lesions (e.g., from strokes) in left temporal or temporo-parietal areas (Goodglass, 1993). We tested one posterior aphasic with a temporo-parietal lesion sparing frontal cortex and the basal ganglia, as well as medial temporal regions (Table 2). As predicted, he produced regulars, which are rule-dependent, more reliably than irregulars, which are memory-dependent (over items, $t(34)=1.56, p=.064)$. He also did well with novel verbs, and overregularized frequently. This pattern is similar to that of the AD subjects, but contrasts with that of the control subjects (Table 3 ).

We replicated the finding with a larger sample of five additional posterior aphasics with less circumscribed lesions (Table 2). These lesions always involved the temporal or parietal lobes, but had extensions to frontal or basal ganglia structures. All five were worse at producing irregular than regular past-tense forms (Table 3). A comparison of the means, with subjects as the error term, yielded $t(4)=3.03, p=.019$; with items as the error term, $t(34)=2.06, p=.024$. (The patients also did better with novel verbs than with irregulars, though this difference was not statistically significant.) The interaction between Irregular/Regular Verb and Posterior Aphasia/Control was statistically significant: $F(1,11)=10.14, p=.009$. In addition, the posterior aphasics produced more overregularizations (range $0-6 \%$ of responses, $0-50 \%$ of errors) than their controls, $t(11)=3.19, p<.005$.

Like $\mathrm{AD}$ patients, posterior aphasics often have more trouble pronouncing irregularly spelled words than regularly spelled and novel ones (Patterson et al., 1985).

\section{IMPAIRMENTS OF GRAMMATICAL RULES}

Parkinson's Disease (PD) is associated with degeneration of dopaminergic neurons in the basal ganglia (substantia nigra), which causes high levels of inhibition of motor and other frontal cortical areas to which the basal ganglia circuits project. This is thought to explain the suppression of movements in PD patients (hypokinesia) (Young \& Penney, 1993), and might account for findings suggesting impairments in the learning of motor, perceptual, and cognitive skills (Bondi \& Kaszniak, 1991; Heindel et al., 1989; Harrington et al., 1991; Saint-Cyr et al., 1988). PD patients also appear to have difficulty with grammar. They have trouble understanding sentences (Grossman et al., 1992; Lieberman et al., 1992), and their spontaneous speech can be syntactically simple (Illes, 1989). In contrast, recognizing words, facts, and events remains relatively unimpaired (Growdon \& Corkin, 1986; Lees \& Smith, 1983; Sagar et al., 1988; Saint-Cyr et al., 1988). The PD pattern is thus complementary to that of AD. If the left basal ganglia project not only to left frontal motor areas, which underlie right-side movement, but also to left frontal areas subserving grammar, right-side hypokinesia should be associated with suppression of 
Table 2. Patient Groups and Their Normal Control Subjects

\begin{tabular}{|c|c|c|c|c|c|c|c|c|c|c|c|c|}
\hline & \multicolumn{2}{|c|}{$\begin{array}{c}\text { Alzbeimer's } \\
\text { disease }(A D)\end{array}$} & \multicolumn{2}{|c|}{$\begin{array}{c}\text { Posterior } \\
\text { apbasia (PA) }\end{array}$} & \multicolumn{2}{|c|}{$\begin{array}{c}\text { Parkinson's } \\
\text { disease (PD) }\end{array}$} & \multicolumn{2}{|c|}{$\begin{array}{c}\text { Anterior } \\
\text { aphasia }(A A)\end{array}$} & \multirow{2}{*}{$\begin{array}{c}\text { Hunt- } \\
\text { ington's } \\
\text { disease } \\
\text { (HD) }\end{array}$} & \multirow[b]{2}{*}{$\begin{array}{c}\text { Control } \\
\text { subjects } \\
(A D, P D)\end{array}$} & \multirow[b]{2}{*}{$\begin{array}{c}\text { Control } \\
\text { subjects } \\
(P A, H D)\end{array}$} & \multirow[b]{2}{*}{$\begin{array}{c}\text { Control } \\
\text { subjects } \\
\text { (AA) }\end{array}$} \\
\hline & $\begin{array}{c}\text { Most } \\
\text { anomic }\end{array}$ & $\begin{array}{c}\text { Full } \\
\text { sample }\end{array}$ & $\begin{array}{l}\text { Pos- } \\
\text { terior } \\
\text { lesion }\end{array}$ & $\begin{array}{l}\text { Larger } \\
\text { lesion }\end{array}$ & $\begin{array}{c}\text { Most } \\
\text { bypo- } \\
\text { kinetic }\end{array}$ & $\begin{array}{c}\text { Full } \\
\text { sample }\end{array}$ & $\begin{array}{c}\text { Frontal } \\
\text { lesion }\end{array}$ & $\begin{array}{l}\text { Larger } \\
\text { lesion }\end{array}$ & & & & \\
\hline$n$ & 5 & 24 & 1 & 5 & 5 & 28 & 1 & 5 & 17 & 14 & 8 & 12 \\
\hline Age $(\mu)$ & 74 & 73 & 49 & 56 & 72 & 69 & 59 & 60 & 45 & 74 & 48 & 63 \\
\hline $\begin{array}{l}\text { Years } \\
\text { educ. }(\mu)\end{array}$ & 14 & 15 & 12 & 14 & 16 & 15 & 15 & 15 & 14 & 16 & 14 & 15 \\
\hline
\end{tabular}

Informed consent was given for all subjects.

Alzheimer's patients: Diagnosed as probable AD without complications according to NINCDS and NLA guidelines (Khachaturian, 1985; McKhann et al., 1984).

- Full sample: 21 native English speakers, 3 bilingual; 22 right-handed, 2 ambidextrous; 16 females.

- The 5 most anomic $\mathrm{AD}$ patients were defined as those with the worst object naming scores: from $7 \%$ to $43 \%$ (the other patients ranged

from $46 \%$ to $92 \%$, with a mean of $68 \%$. 4 native English speakers, 1 bilingual; all right-handed; 4 females.

- AD control subjects: 11 native English speakers, 3 bilingual; all right-handed; 9 females.

Posterior aphasics: - Patient JLU: A right-handed native English speaking male who suffered a stroke 9 months before testing. His lesion consisted of a small patchy area in posterior Wernicke's area, and included posterior supramarginal gyrus, angular gyrus, and a small part of lateral occipital gyrus; medial temporal structures were spared. He had a low score on the Boston Naming Test, largely grammatical spontaneous speech, with some word-finding difficulty, and intact auditory comprehension.

- The larger sample of 5 posterior aphasics had less circumscribed lesions, not limited to temporal and temporo-parietal areas. They were all right-handed native English speakers, with left hemisphere strokes, classified as fluent aphasic with anomia by clinical diagnosis, the Boston Diagnostic Aphasia Exam (Goodglass \& Kaplan, 1972), or the Western Aphasia Battery (Kertesz, 1982). 1. JHA. 60-year-old man, stroke 6 years before testing; occipito-parietal lesion involving supramarginal gyrus, angular gyrus, white matter deep to these areas, portions of superior parietal lobule and occipital lobe; small area of low density in middle frontal gyrus and white matter deep to it. 2. JMO. 64-year-old man, stroke 17 years before testing; lesion involving superior, middle and inferior temporal gyri, white matter deep to them, most of Wernicke's area, the temporal isthmus, area 37, portions of the amygdala and hippocampus, most of the putamen and part of the insula; superior extension involving supramarginal gyrus, angular gyrus, white matter deep to these areas, and superior parietal lobule; posterior extension involving areas 18 and 19 of occipital lobe; frontal lobe spared. 3. HFL. 53-year-old man, stroke 7 years before testing; lesion involving head of caudate nucleus, putamen, globus pallidus, insula, deep white matter pathways, and temporal isthmus. 4. WBO. 55-year-old man, aneurysm 3 years before testing; scarring involving left anterior temporal pole, extending superiorly into frontal lobe just medial to the inferior border of the insular cortex; putamen, thalamus, caudate nucleus, insular cortex spared. 5. APE. 48-year-old woman; patchy temporo-parietal lesion involving the supramarginal gyrus, portions of angular gyrus, white matter deep to them, superior, middle and inferior temporal gyri, white matter deep to them, posterior portions of insular structures, putamen and globus pallidus; the frontal lobe was spared.

- Posterior aphasic control subjects: All right-handed native English speakers; 7 females.

Parkinson's patients: Diagnosed as having PD without complications by their primary neurologist; confirmed by neurologists from the Movement Disorders Unit at Massachusetts General Hospital. No patient was severely demented (IMC dementia score $=<5$ ). Hypokinesia was measured with 4 hand and foot movement subtests of the Unified PD Rating Scale.

- Full sample: 25 native English speakers, 3 bilingual; 26 right-handed, 2 ambidextrous; 6 females. 23 patients were receiving Sinemet. One additional patient was eliminated because of severe byperkinesia, presumably from levodopa medication.

- The 5 most hypokinetic PD patients' right-side hypokinesia scores ranged from 6.5 to 14 with a mean of 10 ; the scores of the remaining 23 PD patients ranged from 0 to 6 with a mean of 3 . All 5 were native English speakers and right-handed; 1 was female.

- The AD control subjects served as the control group for the PD subjects.

Anterior aphasics: - Patient FCL: A right-handed native English speaking male who suffered a stroke 18 years before testing. He had a large left dorsolateral frontal-lobe lesion including almost all of the inferior and middle frontal gyri, all of Broca's area and underlying white matter, and the entire insula. The lenticular nucleus (putamen and globus pallidus) was compromised; the caudate nucleus was spared. A superior extension included the lower two-thirds of the premotor, motor, and somatosensory cortices, and underlying white matter and periventricular white matter. The temporal lobe and remaining parietal lobe were spared. He was classified as Broca's aphasic by clinical diagnosis and the Boston Diagnostic Aphasia Examination (Goodglass \& Kaplan, 1972).

- Six additional anterior aphasics were tested, but their lesions extended to temporal or temporo-parietal areas. Five of them could not perform the past-tense production task. Two of these five were tested in the reading task.

- Anterior aphasic control subjects: All were right-handed native English speakers; 8 were female.

- Five anterior aphasics were given the past-tense reading task. All were right-handed native English speakers with left hemisphere strokes, classified as Broca's aphasic by clinical diagnosis, the Boston Diagnostic Aphasia Exam (Goodglass \& Kaplan, 1972), or the Western Aphasia Battery (Kertesz, 1982). 1. FCL (see above). 2. CIG: 72-year-old woman, stroke 12 years before testing; large posterior frontal-lobe lesion including Broca's area and surrounding structures, the entire insula, the putamen, and anterior supramarginal gyrus; sparing of remaining temporo-parietal and temporal areas, caudate nucleus and globus pallidus. 3. WRO: 52-year-old man, stroke 7 years before testing; large posterior frontal-lobe lesion including Broca's area and surrounding structures, the insula, claustrum, putamen, and anterior segment of the superior temporal gyrus; parietal and remaining temporal lobes spared. 4. LDO: 65-year-old man, stroke 15 years before testing; fronto-parietal lesion including most of Broca's area, with deep extension to the border of the frontal horn, as well as portions of the insula and basal ganglia, and extension into the temporal lobe, including Wernicke's area, temporal isthmus, and anterior supramarginal gyrus. 5. PJ: 51-year-old woman, stroke 11 years before testing; lesion in the frontal lobe, and, to a lesser extent, the parietal and superior temporal lobes.

Huntington's patients: Diagnostic criteria were positive family history and clinical symptoms. HD symptoms, including chorea, were assessed with the Unified Huntington's Disease Rating Scale (UHDRS) (The Huntington's Disease Study Group, 1996).

- All were native English speakers; 13 were right-handed, 2 left-handed, 2 ambidextrous; 5 were female. One patient was taking a dopamine agonist, four were taking dopamine blockers, and two were taking GABA-rgic agonists. One additional patient was tested but was too dysarthric to yield scorable responses.

- The posterior aphasic control subjects served as the control group for the HD subjects. 
Table 3. Past Tense Production and Reading

\begin{tabular}{|c|c|c|c|c|c|c|c|c|c|c|c|}
\hline & & $\begin{array}{c}\text { Alz- } \\
\text { beimer's } \\
\text { disease } \\
(A D) \\
\end{array}$ & $\begin{array}{r}\text { Post } \\
\text { aphas }\end{array}$ & $\begin{array}{l}\text { erior } \\
\text { a }(P A)\end{array}$ & $\begin{array}{c}\text { Parkin- } \\
\text { son's } \\
\text { disease } \\
(P D)\end{array}$ & $\begin{array}{r}\text { Ante } \\
\text { aphasic }\end{array}$ & $\begin{array}{l}\text { rior } \\
a(A A)\end{array}$ & & & & \\
\hline & & $\begin{array}{c}\text { Most } \\
\text { anomic }\end{array}$ & $\begin{array}{l}\text { terior } \\
\text { lesion }\end{array}$ & $\begin{array}{l}\text { Larger } \\
\text { lesion }\end{array}$ & $\begin{array}{c}\text { bypo- } \\
\text { kinetic }\end{array}$ & $\begin{array}{c}\text { Frontal } \\
\text { lesion }\end{array}$ & $\begin{array}{l}\text { Larger } \\
\text { lesion* }\end{array}$ & $\begin{array}{c}\text { disease } \\
(H D)\end{array}$ & $\begin{array}{c}\text { subjects } \\
(A D, H D)\end{array}$ & $\begin{array}{c}\text { subjects } \\
(P A, H D)\end{array}$ & $\begin{array}{c}\text { subjects } \\
(A A)\end{array}$ \\
\hline$n$ & & 5 & 1 & 5 & 5 & 1 & 5 & 17 & 14 & 8 & 12 \\
\hline $\begin{array}{l}\text { Verb Type } \\
\text { Irregular }\end{array}$ & (dig) & & & & & & & & & & \\
\hline Correct & (dug) & $60(7)$ & 63 & $71(9)$ & $88(7)$ & 69 & $52(10)$ & $76(5)$ & $96(1)$ & 99 (1) & $96(2)$ \\
\hline Overregularized & (digged) & $27(6)$ & 25 & $4(1)$ & 0 & 0 & 0 & $8(2)$ & $1(1)$ & 0 & $.5(.5)$ \\
\hline Multiple Suffix & (diggeded) & 0 & 0 & 0 & 0 & 0 & 0 & $1(1)$ & 0 & 0 & $\mathbf{0}$ \\
\hline Syllabic Suffix & $(d i g-i d)$ & 0 & 0 & 0 & 0 & $\mathbf{0}$ & 0 & $.4(.4)$ & 0 & 0 & $\mathbf{0}$ \\
\hline Double Marked & (dugged) & 0 & 6 & $2(1)$ & 0 & $\mathbf{0}$ & 1 (1) & $1(1)$ & 0 & 0 & 0 \\
\hline Ing-Suffixed & (digging) & 0 & 0 & 0 & 0 & 13 & $5(5)$ & $.4(.4)$ & 0 & 0 & 0 \\
\hline Unmarked & (dig) & $17(9)$ & 0 & $14(8)$ & $5(4)$ & 13 & $15(5)$ & $8(3)$ & 0 & $1(1)$ & $.5(.5)$ \\
\hline Overirregularized & (dag) & 0 & 6 & $4(4)$ & $4(3)$ & $\mathbf{0}$ & 0 & $3(2)$ & $1(1)$ & $1(1)$ & $2(1)$ \\
\hline Distortion & (tug) & $\mathbf{0}$ & 6 & $5(2)$ & 0 & 0 & 0 & 0 & 0 & 0 & 0 \\
\hline No response & & 0 & 0 & $2(1)$ & 0 & 0 & $5(3)$ & $1(1)$ & 0 & 0 & 0 \\
\hline Other errors & & 4 & 0 & 3 & 5 & 13 & 24 & 6 & 2 & 0 & 1 \\
\hline Regular & (look) & & & & & & & & & & \\
\hline Correct & (looked) & $89(6)$ & 85 & $83(6)$ & $80(9)$ & 20 & $20(8)$ & $80(6)$ & $98(1)$ & $99(1)$ & $98(1)$ \\
\hline Multiple Suffix & (lookeded) & 0 & 10 & 0 & 0 & 0 & 0 & $5(4)$ & 0 & 0 & 0 \\
\hline Syllabic Suffix & (look-id) & 0 & 0 & 0 & $1(1)$ & 0 & 0 & $1(1)$ & 0 & 0 & 0 \\
\hline Ing-Suffixed & (looking) & 0 & 0 & 0 & 0 & 40 & $6(5)$ & 0 & 0 & 0 & 0 \\
\hline Unmarked & $(l o o k)$ & $5(5)$ & 5 & $12(7)$ & $9(7)$ & 35 & $33(10)$ & $11(3)$ & $1(1)$ & 0 & $1(1)$ \\
\hline Irregularized & $(l a k)$ & 0 & 0 & $1(1)$ & $3(3)$ & 0 & 0 & $1(1)$ & 0 & 0 & 0 \\
\hline Stem Distortion & (rooked) & $1(1)$ & 0 & $1(1)$ & $2(1)$ & 0 & 0 & 0 & 0 & 0 & 0 \\
\hline Word Intrusion & (booked) & 0 & 0 & 0 & $2(2)$ & 0 & 0 & $.3(.3)$ & 0 & 0 & 0 \\
\hline No response & & $5(5)$ & 0 & 0 & 0 & 10 & $8(5)$ & $2(1)$ & $\mathbf{0}$ & $1(1)$ & $.4(.4)$ \\
\hline Other errors & & 0 & 0 & 3 & 9 & 5 & 36 & 3 & .4 & 0 & .4 \\
\hline Novel & (plag) & & & & & & & & & & \\
\hline Correct & (plagged) & $84(9)$ & 80 & $75(12)$ & $65(6)$ & 5 & NA & $72(6)$ & $93(2)$ & $94(2)$ & $96(1)$ \\
\hline Multiple Suffix & (plaggeded) & 0 & 0 & 0 & 0 & 0 & NA & $4(3)$ & $1(.5)$ & $1(1)$ & $.5(.5)$ \\
\hline Syllabic Suffix & (plag-id) & 0 & $\mathbf{0}$ & $1(1)$ & $1(1)$ & 0 & NA & $4(3)$ & 0 & I (1) & $.5(.5)$ \\
\hline Ing-Suffixed & (plagging) & 0 & 0 & 0 & 0 & 30 & NA & 0 & 0 & 0 & 0 \\
\hline Unmarked & (plag) & $3(3)$ & 0 & $13(9)$ & $7(5)$ & 35 & NA & $11(3)$ & 0 & 0 & 0 \\
\hline Irregularized & $(p \log )$ & $3(3)$ & 0 & $1(1)$ & $4(3)$ & $\mathbf{0}$ & NA & $1(1)$ & $2(1)$ & $2(1)$ & $2(1)$ \\
\hline Stem Distortion & (pragged) & $6(2)$ & 10 & $4(2)$ & $17(4)$ & 10 & $\mathbf{N A}$ & $2(1)$ & 0 & 0 & $.4(.4)$ \\
\hline Word Intrusion & (planned) & $1(1)$ & 10 & $3(1)$ & $9(3)$ & 5 & NA & $3(1)$ & 0 & 0 & $0(0)$ \\
\hline No response & & $5(5)$ & 0 & 0 & 0 & 25 & NA & 0 & 0 & 0 & 0 \\
\hline Other errors & & 4 & 0 & 6 & 2 & 0 & NA & 4 & 3 & 2 & .4 \\
\hline Object Naming & & $25(6)$ & 58 & $69(6)$ & $86(4)$ & 65 & $49(8)$ & $74(6)$ & $89(2)$ & $91(2)$ & $89(2)$ \\
\hline
\end{tabular}

Percentage correct and suffixation errors (with standard errors in parentheses) for the past-tense production task (*and, for the larger group of anterior aphasics, for the past-tense reading task). One of the anomic $\mathrm{AD}$ patients, 2 of the HD patients, and 1 of the 5 posterior aphasics were unable to learn novel verbs; group means for the $\mathrm{AD}, \mathrm{HD}$, and posterior aphasic groups for novel verbs were calculated over the remaining patients. Object naming scores were available for only 3 of the 5 anterior aphasics with larger lesions; the group mean is calculated from their responses. Percentages may add up to more than $100 \%$ because of rounding and because patients sometimes made more than one error for a given item. 
rule programming, and therefore with difficulty producing rule-generated past-tense forms.

As with the $\mathrm{AD}$ patients, our predictions do not apply to all people diagnosed with the syndrome. They apply only to those with a sufficiently severe case of the relevant symptom, in this case hypokinesia. The predictions may be tested in two ways. One test examines a correlation across the entire group of patients: the greater the hypokinesia, the greater the predicted difficulty inflecting regular and novel verbs (though not irregular verbs). The second test focuses on the subset of patients with the most severe hypokinesia. They should have greater difficulty inflecting regular and novel verbs than irregular verbs, and should make few overregularization errors.

We gave 28 PD patients (Table 2) the same tests as the $\mathrm{AD}$ subjects, and rated their hypokinesia on the Unified PD Rating Scale (Fahn \& Elton, 1987). Across the 28 patients, right-side hypokinesia (irrespective of left-side hypokinesia) correlated significantly with difficulties producing regular verbs, and with difficulties producing novel verbs, but not with difficulties producing irregular verbs. These findings remained even when IMC dementia scores were partialed out (Table 4). The role of the left basal ganglia in rule processing was underscored by the finding that this pattern of correlations with right-side hypokinesia remained when left-side hypokinesia was partialed out, while none of the correlations of past- tense performance with left-side hypokinesia was significant with right-side hypokinesia partialed out (Table 4).

In the second test, the five patients with the most severe right-side hypokinesia were selected (Tables 2 and 3). They inflected irregular verbs more reliably than they inflected regular verbs. In an Analysis of Variance, the interaction between Regular/Irregular Verb and PD/Control yielded $F(1,17)=7.65, p=.013$; with IMC covaried out, $F(1, \mathrm{I} 6)=5.82, p=.028$. The hypokinetic PD group was marginally worse at regulars than irregulars: with subjects as the error term, $t(4)=1.98, p=.059$; with items, $t(34)=1.34, p=.095$. The control subjects showed the opposite pattern. The hypokinetic PD patients also performed better with irregulars than with novel verbs, which have the greatest demand on rule processing. The interaction between Irregular/Novel Verb and PD/Control yielded $F(1,17)=21.03, p<.005$; with IMC covaried out, $F(1,16)=20.10, p<.005$. The patients were significantly worse at inflecting novel verbs than irregulars: with subjects as the error term, $t(4)=10.47, p<.001$; with items, $t(34)=3.49, p<.001$. Though $12 \%$ of the irregular items elicited errors, none were overregularizations.

The $\mathrm{PD}$ and $\mathrm{AD}$ groups, since they are predicted to show complementary deficits in rules and lexicon, may be contrasted directly. The interaction between Irregular/Regular Verb and AD/PD was statistically significant, $F(1,8)=13.13, p=.007$; with IMC covaried out, $F(1,7)$

Table 4. Correlations

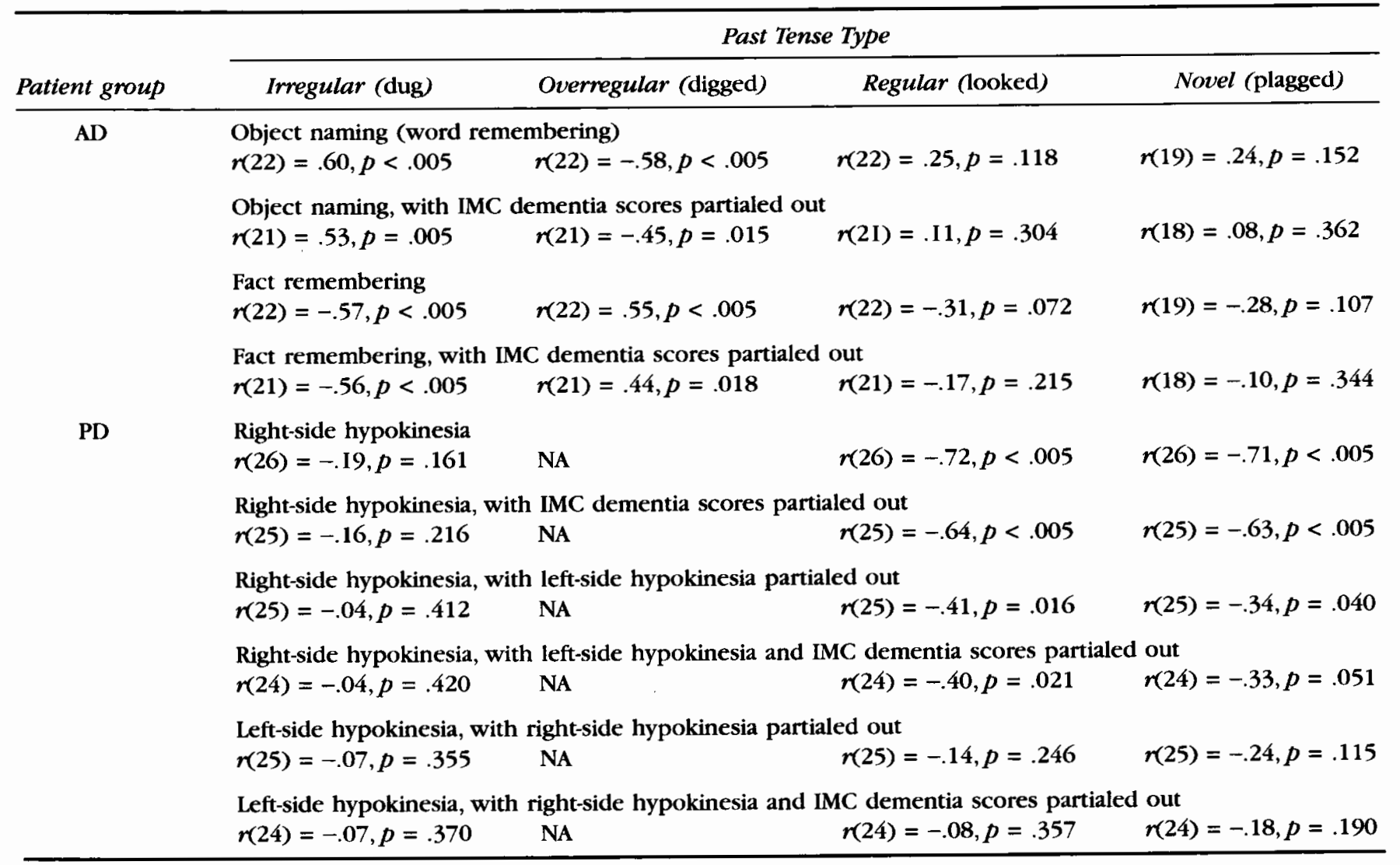


$=21.46, p=.002$. Similarly, the interaction between Irregular/Novel Verb and AD/PD yielded $F(1,7)=10.73$, $p=.014 ;$ with IMC covaried out, $F(1,6)=23.70, p=.003$.

PD patients often show dysarthria (Dubois et al., 1991). It is important to show that their deficit with regular past forms is not simply a difficulty in articulating the final consonant cluster (e.g., looked versus $d u g$ ). We assembled three sets of 21 items matched for final consonant structure but differing in rule demands: regulars, irregulars, and uninflected forms (e.g., passed-lost-fast) (Table 1). Of the five hypokinetic PD subjects, four were available for retest. They had no trouble repeating the uninflected words with final consonant cluster intact (mean 98\%; range 95-100\%), and were more successful inflecting the irregulars (87\%) than the regulars $(70 \%)$; with subjects as the error term, $t(3)=1.85, p=.081$; with items, $t(20)=3.01, p<.005$. All subjects showed the difference, ranging from 5 to 43 percentage points.

The PD patients' relative difficulty with the regulars was also not attributable to their lower frequencies. A subset of six regular verbs and six irregular verbs was selected from the matched set, such that the frequencies of the regular and irregular items, in addition to their final consonant structure, was equated. (In fact, the regular members had a slightly bigher mean past tense frequency; see Table 1.) The advantage for irregulars persisted in this subset (92\% versus $58 \%$ ). All subjects showed the difference, ranging from 17 to 67 percentage points; the means were significantly different when tested with subjects as the error term, $t(3)=2.83, p=$ .033 , and with items as the error term, $t(5)=3.16, p=$ .013 .

Anterior Aphasia is characterized by "agrammatism" (omission or misuse of grammatical morphemes, and difficulty understanding sentences) and articulation problems, while access to content words such as verbs and nouns is often relatively spared. It is associated with lesions to Broca's area and adjacent left frontal perisylvian cortex, plus underlying white matter and the basal ganglia, though many patients diagnosed with anterior aphasia have much larger lesions (Damasio, 1992; Goodglass, 1993). We tested one agrammatic anterior aphasic whose lesion included frontal cortex and the basal ganglia but spared temporo-parietal and temporal regions (Table 2). As predicted, he was better at inflecting irregular verbs than regular verbs; the difference between means was statistically significant, $t(34)=3.29$, $p=.001$, items within verb classes serving as the error term. He was also better at inflecting irregular verbs than novel verbs: $t(34)=5.29, p<.001$. The patient never overregularized. This pattern is similar to that of the PD subjects, but contrasts with that of the control, $\mathrm{AD}$, and posterior aphasic subjects (Table 3 ).

The relative problem with regulars was not caused by their lower frequencies. In a frequency-matched subset (chosen by eliminating the five most frequent irregulars and the six least frequent regulars; see Table 1), the irregular-regular difference persisted (64\% versus $21 \%$; $t(23)=2.27, p=.017$, with items serving as the error term).

To rule out frequency and articulatory effects, and to use an easier task that even patients with larger lesions could perform, we asked five agrammatic anterior aphasics (Table 2) to read aloud a randomly-ordered list of 17 regular and 17 irregular past forms matched pairwise for stem and past-tense frequencies and for final consonant structure (e.g., slipped-swept) (Table 1). Previous case studies on such aphasics (Badecker \& Caramazza, 1987; Badecker \& Caramazza, 1991; Marin et al., 1976) had found an advantage for reading irregulars over regulars, even when word frequency, length, and presence of common embedded words (looked, dogma, cf. look, dog) were controlled for. Each of our five patients also showed this difference ( $52 \%$ versus $20 \%$; see Table 3 ). The difference was statistically significant with subjects as the error term, $t(4)=10.85, p<.005$, and with items as the error term $t(32)=3.78, p<.001$. Interestingly, agrammatic anterior aphasics also commonly have more difficulty pronouncing novel and regularly spelled words, which depend on rules, than irregularly spelled words, which depend on memory (Goodglass, 1993). The pattern is opposite to that found in AD and posterior aphasia.

\section{A ROIE FOR THE BASAL GANGLIA IN GRAMMATICAL RULE PROCESSING}

In PD patients, the suppression of motor programming (caused by basal ganglia degeneration leading to the inhibition of frontal cortical areas) was associated with a suppression of rule programming. A complementary demonstration of a role for the basal ganglia in rule programming comes from Huntington's Disease (HD). Like PD, HD is accompanied by a loss of neurons in the basal ganglia (caudate and putamen), but, unlike PD, it is often in the inhibitory "indirect" pathway (Reiner et al., 1988). This causes excess excitation in motor and other frontal cortical areas receiving basal ganglia projections. It is thought to explain why HD patients have unsuppressible movements, or chorea, a type of byperkinesia (Young \& Penney, 1993). Degeneration leading to such excess movements may therefore also lead to excess rule use.

We tested $17 \mathrm{HD}$ patients and 8 control subjects (Table 2). The HD patients inflected irregular, regular, and novel verbs at similar success rates (all $p s>.1$ ). However, they overregularized the irregulars (digged) $8 \%$ of the time; 11 patients made these errors, at rates ranging from $6 \%$ to $25 \%$. The group's overregularization rate was significantly higher than that of their control subjects $(0 \%$; $t(23)=2.73, p=.006$, with subjects as error term). The HD patients also produced two kinds of unusual errors, primarily on regular and novel verbs: multiply suffixed forms, like lookeded, and syllabically suffixed forms, like 
look-id. These errors occurred $6 \%$ of the time, and were made by nine of the patients (one at a rate of $76 \%$, the others from $2-11 \%$ ). In contrast, they were made $0.2 \%$ of the time by their control subjects, $1 \%$ of the time by the $24 \mathrm{AD}$ patients, and $0.2 \%$ of the time by the $28 \mathrm{PD}$ patients. The difference between the HD and control subjects was significant (Mann-Whitney $U \chi^{2}(1)=3.64$, $p=.028$, one-tailed; nonparametric test used because of the outlier HD patient). These errors do not appear to be motor perseverations or exaggerations: irregular past forms ending with $t$ or $d$ (e.g., kept, bent) elicited no perseverations of the final consonant (keptit, 0 out of 170 opportunities), and only one syllabic pronunciation (kep-it, 1 out of 51 opportunities). Across the HD patients, the chorea measure correlated significantly with the rate of producing overregularizations $(r(15)=.42, p$ $=.047)$, and with the rate of producing multiply or syllabically suffixed forms $\left(r_{\rho}(15)=.57, p=.009\right.$; Spearman rank correlation used because of the outlier). This was also true when IMC dementia scores were partialed out (respectively, $r(14)=.48, p=.031$, and $r_{\rho}(14)=.54$, $p=.016$ ).

Although both the $\mathrm{AD}$ and $\mathrm{HD}$ patients overregularized, they are predicted to have done so for different reasons: deficient word-finding for the $\mathrm{AD}$ patients, but overactive rules for the $\mathrm{HD}$ patients. Unlike the five anomic AD patients, the HD patients' object-naming scores were close to those of their control subjects (Table 3), and, across all 17 HD patients, naming did not correlate with overregularization rates $(r(15)=-.24, p=$ .178). A measure of overall disease progression (Shoulson \& Fahn, 1979) did not correlate with chorea $(r(15)=$ $-.01, p=.478$ ), and the measure also did not correlate with rates of overregularization $(r(15)=-.13, p=.310)$ or multiple and syllabic suffixing $(r(15)=.05, p=.421)$. This suggests that it is the specific kind of lesion leading to chorea that also leads to overactive rule use. In sum, chorea in HD is associated with superfluous addition of $-e d$, as if the suffixing rule was too active, both to regular forms, which should have only one suffix, and to irregular stems, which should not have any. Because the -ed in overregularization errors (digged) is not present in correct irregular forms (dug), such errors cannot be attributed to motor perseverations or exaggerations of the $-t$ or $-d$. This further suggests a role for the basal ganglia in the rule-programming system.

\section{CONCLUSION}

Patients with relative damage to temporal or parietal neocortex, and with general impairments of declarative memory (in Alzheimer's disease) or specifically of lexical memory (in posterior aphasia), had more trouble converting irregular verbs to their past tense forms than regular or novel verbs, and overgeneralized the suffix. Patients with relative damage to the frontal/basal-ganglia system, and with general impairments of procedures (in
Parkinson's disease) or specifically of grammar (in anterior aphasia), showed the opposite pattern. These results support psycholinguistic theories that emphasize grammar and lexicon as distinct components over those that minimize or eliminate either, especially in the treatment of regular and irregular grammatical phenomena. Moreover, the findings extend the distinction between the temporal-parietal/medial-temporal declarative memory system and the frontal/basal-ganglia procedural system to the two major components of human language. Finally, one kind of basal ganglia lesion, which leads to the suppression of motor activity (in Parkinson's disease), also led to the suppression of rule use. In contrast, another kind of basal ganglia lesion, which leads to excess motor activity (in Huntington's disease), also led to excess rule use. This bears out Damasio and Damasio's (1992) hypothesis that basal ganglia circuitry contributes to grammatical rule processing in conjunction with frontal cortex, and suggests that the well-studied basal ganglia circuits underlying motor programming may play a comparable role in rule programming.

\section{Acknowledgments}

This study was supported by the McDonnell-Pew Center for Cognitive Neuroscience at MIT for M.U. and S.P., NIH Grant HD 18381 and NSF Grant BNS 91-09766 to S.P; AG06605 and AGNS08117 to S.C.; AG05134 to J.G.; and DC00081 and AG10496 to Edgar Zurif. The work was carried out while M. Ullman was a McDonnell-Pew Postdoctoral Fellow in Cognitive Neuroscience in the Department of Brain and Cognitive Sciences (BCS) and the Clinical Research Center at MIT; M. Coppola was a Research Assistant at MIT; G. Hickok was a McDonnell-Pew Postdoctoral Fellow in Cognitive Neurosciences at BCS at MIT. We thank Joseph Locascio for statistical advice, Cheryl McSweeney for testing patients, Nina Dronkers, Sulochana Naidoo, Eleanor Saffran, and Edgar Zurif for referring aphasic subjects, and Antonio Damasio and two anonymous referees for helpful comments.

Reprint requests should be sent to Michael Ullman, Institute for Cognitive and Computational Sciences, Georgetown University, 3970 Reservoir Road, NW, Washington, D.C. 20007. Phone: 202-687-6896. Fax: 202-687-0617. Email: ullmanm@ giccs. georgetown.edu

\section{REFERENCES}

Alexander, G., Crutcher, M., \& De Long, M. (1990). Basal ganglia-thalamocortical circuits: Parallel substrates for motor, oculomotor, "prefrontal" and "limbic" functions. Progress in Brain Research, 85, 119-146.

Arnold, S., Hyman, B., Flory, J., Damasio, A., \& Hoesen, G. V. (1991). The topographical and neuroanatomic distribution of neurofibrillary tangles and neuritic plaques in the cerebral cortex of patients with Alzheimer's disease. Cerebral Cortex, 1, 103-116.

Badecker, W., \& Caramazza, A. (1987). The analysis and morphological errors in a case of acquired dyslexia. Brain and Language 32, 278-305.

Badecker, W., \& Caramazza, A. (1991). Morphological composition in the lexical output system. Cognitive Neuroscience, 8, 335-367. 
Balota, D., \& Ferraro, R. (1993). A dissociation of frequency and regularity effects in pronunciation performance across young adults, older adults, and individuals with senile dementia of the Alzheimer type. Journal of Memory and Language, 32, 573-592.

Bates, E., \& Wulfeck, B. (1989). Crosslinguistic studies of aphasia. In B. MacWhinney, \& E. Bates (Eds.), The crosslinguistic study of sentence processing (pp. 328-371). New York: Cambridge University Press.

Beatty, W., Winn, P., Adams, R., Allen, E., Wilson, D., Prince, J., Olson, K., Dean, K., \& Littleford, D. (1994). Preserved cognitive skills in dementia of the Alzheimer type. Arcbives of Neurology, 51, 1040-1046.

Blessed, G., Tomlinson, B. E., \& Roth, M. (1968). The association between quantitative measures of dementia and of senile change in the cerebral grey matter of elderly subjects. Britisb Journal of Psycbiatry 114, 797-811.

Bondi, M. W., \& Kaszniak, A. W. (1991). Implicit and explicit memory in Alzheimer's disease and Parkinson's disease. Journal of Clinical and Experimental Neuropsycbology 13, 339-358.

Chomsky, N. (1965). Aspects of the theory of syntax. Cambridge, MA: MIT Press.

Chomsky, N., \& Halle, M. (1968). The sound pattern of English. New York: Harper and Row.

Cohen, N., \& Squire, L. (1980). Preserved learning and retention of pattern-analyzing skill in amnesia: Dissociation of knowing how and knowing that. Science, 210, 207-210.

Corkin, S. (1982). Some relationships between global amnesias and the memory impairments in Alzheimer's disease. In S. Corkin, K. Davis, J. Growdon, \& E. Usdin (Eds.), Alzbeimer's disease (pp. 149-164). New York: Raven Press.

Damasio, A. R. (1992). Aphasia. New England Journal of Medicine, 326, 531-539.

Damasio, A. R., \& Damasio, H. (1992). Brain and language. Scientific American, 267(3), 88-95.

De Saussure, F. (1916/1959). A course in general linguistics. London: Peter Owen.

Dubois, B., Boller, F., Pillon, B., \& Agid, Y. (1991). Cognitive deficits in Parkinson's disease. In F. Boller, J. Grafman, \& S. Corkin (Eds.), Handbook of neuropsycbology (Vol. 5 , pp. 195-240). Amsterdam: Elsevier

Fahn, S., \& Elton, R. (1987). Unified Parkinson's disease rating scale. In C. Marsden, \& M. Goldstein (Eds.), Recent developments in Parkinson's disease II (pp. 153-163). New York: MacMillan.

Francis, N., \& Kucera, H. (1982). Frequency analysis of English usage: Lexicon and grammar. Boston: Houghton Mifflin.

Gabrieli, J., Corkin, S., Mickel, S., \& Growdon, J. (1993). Intact acquisition and long term retention of mirror-tracing skill in Alzheimer's disease and in global amnesia. Behavioral Neuroscience, 107, 899-910.

Geschwind, N. (1965). Disconnexion syndromes in animals and man. Brain, 88, 237-294.

Goodglass, H. (1993). Understanding apbasia. San Diego: Academic Press.

Goodglass, H., \& Kaplan, E. (1972). The assessment of apbasia and related disorders. Philadelphia: Lea and Febiger.

Goodglass, H., Kaplan, E., \& Weintraub, S. (1983). Boston naming test. Philadelphia: Lea and Febiger.

Grossman, M., Carvell, S., Stern, M. B., Gollomp, S., \& Hurtig, H. I. (1992). Sentence comprehension in Parkinson's disease: The role of attention and memory. Brain and Language, 42, 347-384.

Growdon, J., \& Corkin, S. (1986). Cognitive impairments in Parkinson's disease. In M. Yahr, \& K. Bergmann (Eds.), Ad- vances in neurology (Vol. 45, pp. 383-392). New York: Raven Press.

Halle, M., \& Mohanon, K. P. (1985). Segmental phonology of modern English. Linguistic Inquiry, 16, 57-116.

Hare, M., \& Elman, J. (1995). Learning and morphological change. Cognition, 56, 61-98.

Harrington, D., Haaland, K., Yeo, R., \& Marder, E. (1991). Procedural memory in Parkinson's disease: Impaired motor but not visuoperceptual learning. Journal of Clinical and ExDerimental Neurobsvcbology 12, 323-339.

Heindel, W., Salmon, D., Shults, C., Walicke, P., \& Butters, N. (1989). Neuropsychological evidence for multiple implicit memory systems: A comparison of Alzheimer's, Huntington's, and Parkinson's disease. Journal of Neuroscience, 9, 582-587.

Hoover, J., \& Strick, P. (1993). Multiple output channels in the basal ganglia. Science, 259, 819-821.

Huntington's Study Group, The (1996). Unified Huntington's disease rating scale: Reliability and consistency. Movement Disorders, I1(2), 136-142.

Illes, J. (1989). Neurolinguistic features of spontaneous language production dissociate three forms of neurogenerative disease: Alzheimer's, Huntington's, and Parkinson's. Brain and Lanquave, 37(4), 628-642.

Irigaray, L. (1973). Le langage des déments. The Hague: Mouton.

Kemper, T. (1994). Neuroanatomical and neuropathological changes during aging and dementia. In $\mathbf{M}$. Albert, \& $\mathrm{J}$. Knoefel (Eds.), Clinical neurology of aging (pp. 3-67). New York: Oxford University Press.

Kertesz, A. (1982). Western apbasia battery. New York: Grune and Stratton.

Khachaturian, Z. (1985). Diagnosis of Alzheimer's disease. Arcbives of Neurology, 42, 1097-1105.

Kluender, R., \& Kutas, M. (1993). Bridging the gap: Evidence from ERP's on the processing of unbounded dependencies. Journal of Cognitive Neuroscience, 5, 196-214

Lees, A., \& Smith, E. (1983). Cognitive deficits in the early stages of Parkinson's disease. Brain, 106, 257-270.

Lieberman, P., Kako, E., Friedman, J., Tajchman, G., Feldman, L. S., \&.Jiminez, E. B. (1992). Speech production, syntax comprehension, and cognitive deficits in Parkinson's disease. Brain and Lanquage. 43, 169-189.

Ling, C. X., \& Marinov, M. (1993). Answering the connectionist challenge: A symbolic model of learning the past tenses of English verbs. Cognition, 49(3), 235-296.

MacWhinney, B., \& Leinbach, J. (1991). Implementations are not conceptualizations: Revising the verb learning model. Cognition 40, 121-157.

Marcus, G., Brinkmann, U., Clahsen, H., Wiese, R., \& Pinker, S. (1995). German inflection: The exception that proves the rule. Cognitive Psucbology, 29, 189-256.

Marcus, G. F., Pinker, S., Uliman, M., Hollander, M., Rosen, T. J., \& Xu, F. (1992). Overregularization in language acquisition. Monographs of the Society for Research in Child Development, 57(4).

Marin, O., Saffran, E., \& Schwartz, M. (1976). Dissociations of language in aphasia: Implications for normal function. $A \boldsymbol{n}$ nals of the New York Academy of Sciences, 280, 868-884.

McKhann, G., Drachman, D., Folstein, M., Katzman, R., Price, D., \& Stadlan, E. M. (1984). Clinical diagnosis of Alzheimer's disease: Report of the NINCDS-ADRDA work group under the auspices of Department of Health and Human Services task force on Alzheimer's disease. Neurology, 34, 939-944.

Middleton, F, \& Strick, P. (1994). Anatomical evidence for cerebellar and basal ganglia involvement in higher cognitive function. Science, 266, 458-461. 
Mishkin, M., Malamut, B., \& Bachevalier, J. (1984). Memories and habits: Two neural systems. In G. Lynch, J. McGaugh, \& $\mathrm{N}$. Weinberger (Eds.), Neurobiology of learning and memory (pp. 65-77). New York: Guilford.

Nebes, R. D. (1989). Semantic memory in Alzheimer's disease. Psvcbological Bulletin. 106, 377-394.

Neville, H., Nicol, J. L., Barss, A., Forster, K. I., \& Garrett, M. F. (1991). Syntactically based sentence processing classes: Evidence from event-related brain potentials. Journal of Cognitive Neuroscience, 3, 151-165.

Patterson, K. E., Marshall, J. C., \& Coltheart, M. (1985). Surface dyslexia. London: Erlbaum.

Pinker, S. (1991). Rules of language. Science 253, 530-535.

Pinker, S. (1994). The language instinct. New York: William Morrow.

Pinker, S., \& Prince, A. (1988). On language and connectionism: Analysis of a parallel distributed processing model of language acquisition. Cognition, 28, 73-193.

Plunkett, K., \& Marchman, V. (1993). From rote learning to system building: Acquiring verb morphology in children and connectionist nets. Connition, 48, 21-69.

Prasada, S., \& Pinker, S. (1993). Generalization of regular and irregular morphological patterns. Language and Cognitive Processes 8, 1-56.

Preuss, T. (1995). The argument from animals to humans in cognitive neuroscience. In M. Gazzaniga (Ed.), The cognitive neurosciences. Cambridge, MA: MIT Press.

Reiner, A., Albin, R., Anderson, K., D'Amato, C., Penney, J., \& Young, A. (1988). Differential loss of striatal projection neurons in Huntington's disease. Proceedings of the National Academv of Sciences. USA, 85, 5733-5737.

Rumelhart, D., \& McClelland, J. (1986). On learning the past tenses of English verbs: Implicit rules or parallel distrib- uted processing? In J. McClelland, D. Rumelhart, \& the PDP Research Group (Eds.), Parallel Distributed Processing (pp. 216-271). Cambridge, MA: MIT Press.

Sagar, H., Cohen, N., Sullivan, E., Corkin, S., \& Growdon, J. (1988). Remote memory function in Alzheimer's and Parkinson's disease. Brain. 111, 185-206.

Saint-Cyr, J., Taylor, A., \& Lang, A. (1988). Procedural learning and neostriatal dysfunction in man. Brain, 111, 941-959.

Schwartz, M. F, Marin, O. S. M., \& Saffran, E. M. (1979). Dissociations of language function in dementia: A case study. Brain and Language, 7, 277-306.

Shoulson, I., \& Fahn, S. (I979). Huntington's disease: Clinical care and evaluation. Neurology, 29, I-3.

Squire, L. R., Knowlton, B., \& Musen, G. (1993). The structure and organization of memory. Annual Review of Psycbology 44, 453-495.

Stromswold, K., Caplan, D., Alpert, N., \& Rausch, S. (1996). Localization of syntactic comprehension by positron emission tomography. Brain and Language, 52(3), 452-473.

Suzuki, W., and Amaral, D. (1994). Perirhinal and parahippocampal cortices of the macaque monkey: Cortical afferants.Journal of Comparative Neurology, 350, 497-533.

Warrington, E. K. (1975). The selective impairment of semantic memory. Quarterly Journal of Experimental Psychology, 27, 635-657.

Wernicke, C. (1874). Der aphasiche Symptomenkomplex. Breslau: Cohn und Weigert.

Young, A., \& Penney, J. (1993). Biochemical and functional organization of the basal ganglia. In J. Jankovic, \& E. Tolosa (Eds.), Parkinson's disease and movement disorders, (pp. 1-11). Baltimore: Williams and Wilkins. 


\section{This article has been cited by:}

1. David Eddington. 2009. Spanish verbal inflection: a single- or dual-route system?. Linguistics 47:1, 173-199. [CrossRef]

2. Victor S. Ferreira, Kathryn Bock, Michael P. Wilson, Neal J. Cohen. 2008. Memory for Syntax Despite Amnesia. Psychological Science 19:9, 940-946. [CrossRef]

3. Marc D. Pell, Laura Monetta. 2008. How Parkinson's Disease Affects Non-verbal Communication and Language Processing. Language and Linguistics Compass 2:5, 739-759. [CrossRef]

4. Matthew Walenski, Stewart H. Mostofsky, Jennifer C. Gidley-Larson, Michael T. Ullman. 2008. Brief Report: Enhanced Picture Naming in Autism. Journal of Autism and Developmental Disorders 38:7, 1395-1399. [CrossRef]

5. Kaoru Takahashi, Fu-Chin Liu, Takao Oishi, Takuma Mori, Noriyuki Higo, Motoharu Hayashi, Katsuiku Hirokawa, Hiroshi Takahashi. 2008. Expression of FOXP2 in the developing monkey forebrain: Comparison with the expression of the genes FOXP1 , PBX3 , and MEIS2. The Journal of Comparative Neurology 509:2, 180-189. [CrossRef]

6. TANIA GIOVANNETTI, MARY W. HOPKINS, JACLYN CRAWFORD, BRIANNE MAGOUIRK BETTCHER, KARA S. SCHMIDT, DAVID J. LIBON. 2008. Syntactic comprehension deficits are associated with MRI white matter alterations in dementia. Journal of the International Neuropsychological Society 14:04. . [CrossRef]

7. Marinella Cappelletti, Felipe Fregni, Kevin Shapiro, Alvaro Pascual-Leone, Alfonso Caramazza. 2008. Processing Nouns and Verbs in the Left Frontal Cortex: A Transcranial Magnetic Stimulation StudyProcessing Nouns and Verbs in the Left Frontal Cortex: A Transcranial Magnetic Stimulation Study. Journal of Cognitive Neuroscience 20:4, 707-720. [Abstract] [PDF] [PDF Plus]

8. ELENA NICOLADIS. 2007. The effect of bilingualism on the use of manual gestures. Applied Psycholinguistics 28:03. . [CrossRef]

9. Elizabeth S. Norton, Ioulia Kovelman, Laura-Ann Petitto. 2007. Are There Separate Neural Systems for Spelling? New Insights into the Role of Rules and Memory in Spelling from Functional Magnetic Resonance Imaging. Mind, Brain, and Education 1:1, 48-59. [CrossRef]

10. Ruth de Diego Balaguer, Antoni Rodríguez-Fornells, Michael Rotte, Jörg Bahlmann, Hans-Jochen Heinze, Thomas F. Münte. 2006. Neural circuits subserving the retrieval of stems and grammatical features in regular and irregular verbs. Human Brain Mapping 27:11, 874-888. [CrossRef]

11. Marc Teichmann, Emmanuel Dupoux, Sid Kouider, Anne-Catherine Bachoud-Lévi. 2006. The Role of the Striatum in Processing Language Rules: Evidence from Word Perception in Huntington's DiseaseThe Role of the Striatum in Processing Language Rules: Evidence from Word Perception in Huntington's Disease. Journal of Cognitive Neuroscience 18:9, 1555-1569. [Abstract] [PDF] [PDF Plus]

12. Satoru Yokoyama, Tadao Miyamoto, Jorge Riera, Jungho Kim, Yuko Akitsuki, Kazuki Iwata, Kei Yoshimoto, Kaoru Horie, Shigeru Sato, Ryuta Kawashima. 2006. Cortical Mechanisms Involved in the Processing of Verbs: An fMRI StudyCortical Mechanisms Involved in the Processing of Verbs: An fMRI Study. Journal of Cognitive Neuroscience 18:8, 1304-1313. [Abstract] [PDF] [PDF Plus]

13. MICHAEL P. ALEXANDER. 2006. Impairments of procedures for implementing complex language are due to disruption of frontal attention processes. Journal of the International Neuropsychological Society 12:02 . . [CrossRef]

14. Michael T. Ullman. 2006. The declarative/procedural model and the shallow structure hypothesis. Applied Psycholinguistics 27:01. . [CrossRef]

15. Joshua K. Hartshorne, Michael T. Ullman. 2006. Why girls say 'holded' more than boys. Developmental Science 9:1, 21-32. [CrossRef]

16. C. E. Longworth , W. D. Marslen-Wilson , B. Randall , L. K. Tyler . 2005. Getting to the Meaning of the Regular Past Tense: Evidence from NeuropsychologyGetting to the Meaning of the Regular Past Tense: Evidence from Neuropsychology. Journal of Cognitive Neuroscience 17:7, 1087-1097. [Abstract] [PDF] [PDF Plus]

17. Michele Miozzo , Peter Gordon . 2005. Facts, Events, and Inflection: When Language and Memory DissociateFacts, Events, and Inflection: When Language and Memory Dissociate. Journal of Cognitive Neuroscience 17:7, 1074-1086. [Abstract] [PDF] [PDF Plus]

18. Susanne Reiterer, Michael L. Berger, Claudia Hemmelmann, Peter Rappelsberger. 2005. Decreased EEG coherence between prefrontal electrodes: a correlate of high language proficiency?. Experimental Brain Research 163:1, 109-113. [CrossRef]

19. Christian J. Fiebach, Sandra H. Vos, Angela D. Friederici. 2004. Neural Correlates of Syntactic Ambiguity in Sentence Comprehension for Low and High Span ReadersNeural Correlates of Syntactic Ambiguity in Sentence Comprehension for Low and High Span Readers. Journal of Cognitive Neuroscience 16:9, 1562-1575. [Abstract] [PDF] [PDF Plus] 
20. Lorraine K. Tyler, Emmanuel A. Stamatakis, Roy W. Jones, Peter Bright, Kadia Acres, William D. Marslen-Wilson. 2004. Deficits for Semantics and the Irregular Past Tense: A Causal Relationship?Deficits for Semantics and the Irregular Past Tense: A Causal Relationship?. Journal of Cognitive Neuroscience 16:7, 1159-1172. [Abstract] [PDF] [PDF Plus]

21. Marc F. Joanisse. 2004. Specific Language Impairments in Children. Phonology, Semantics, and the English Past Tense. Current Directions in Psychological Science 13:4, 156-160. [CrossRef]

22. SONJA A. KOTZ, STEFAN FRISCH, D. YVES VON CRAMON, ANGELA D. FRIEDERICI. 2003. Syntactic language processing: ERP lesion data on the role of the basal ganglia. Journal of the International Neuropsychological Society 9:07. . [CrossRef]

23. DAVID COPLAND. 2003. The basal ganglia and semantic engagement: Potential insights from semantic priming in individuals with subcortical vascular lesions, Parkinson's disease, and cortical lesions. Journal of the International Neuropsychological Society 9:07. . [CrossRef]

24. Kenichi MEGURO, Mirna LH SENAHA, Paulo CARAMELLI, Junichi ISHIZAKI, Rosa YS CHUBACCI, Mitsue MEGURO, Hideo AMBO, Ricardo NITRINI, Atsushi YAMADORI. 2003. Language deterioration in four Japanese-Portuguese bilingual patients with Alzheimer's disease: a trans-cultural study of Japanese elderly immigrants in Brazil. Psychogeriatrics 3:2, 63-68. [CrossRef]

25. Randi C. Martin. 2003. Language Processing: Functional Organization and Neuroanatomical Basis. Annual Review of Psychology 54:1, 55-89. [CrossRef]

26. Morton Ann Gernsbacher, Michael P. Kaschak. 2003. Neuroimaging Studies of Language Production and Comprehension. Annual Review of Psychology 54:1, 91-114. [CrossRef]

27. Michael S. C. Thomas, Annette Karmiloff-Smith. 2003. Modeling language acquisition in atypical phenotypes. Psychological Review 110:4, 647-682. [CrossRef]

28. Angela D. Friederici, Sonja A. Kotz, Katja Werheid, Grit Hein, D. Yves von Cramon. 2003. Syntactic comprehension in Parkinson's disease: Investigating early automatic and late integrational processes using event-related brain potentials. Neuropsycbology 17:1, 133-142. [CrossRef]

29. Antoni Rodriguez-Fornells, Thomas F. Münte, Harald Clahsen . 2002. Morphological Priming in Spanish Verb Forms: An ERP Repetition Priming StudyMorphological Priming in Spanish Verb Forms: An ERP Repetition Priming Study. Journal of Cognitive Neuroscience 14:3, 443-454. [Abstract] [PDF] [PDF Plus]

30. Stanley B. Klein, Leda Cosmides, John Tooby, Sarah Chance. 2002. Decisions and the evolution of memory: Multiple systems, multiple functions. Psychological Review 109:2, 306-329. [CrossRef]

31. Lorraine K. Tyler , Paul deMornay-Davies, Rebekah Anokhina, Catherine Longworth , Billi Randall, William D. Marslen-Wilson . 2002. Dissociations in Processing Past Tense Morphology: Neuropathology and Behavioral StudiesDissociations in Processing Past Tense Morphology: Neuropathology and Behavioral Studies. Journal of Cognitive Neuroscience 14:1, 79-94. [Abstract] [PDF] [PDF Plus]

32. Michael T. Ullman. 2001. A neurocognitive perspective on language: The declarative/procedural model. Nature Reviews Neuroscience 2:10, 717-726. [CrossRef]

33. Karsten Steinhauer, Roumyana Pancheva, Aaron J. Newman, Silvia Gennari, Michael T. Ullman. 2001. How the mass counts: An electrophysiological approach to the processing of lexical features. Neuroreport 12:5, 999-1005. [CrossRef]

34. Thomas Goschke, Angela D. Friederici, Sonja A. Kotz, Anja van Kampen. 2001. Procedural Learning in Broca's Aphasia: Dissociation between the Implicit Acquisition of Spatio-Motor and Phoneme SequencesProcedural Learning in Broca's Aphasia: Dissociation between the Implicit Acquisition of Spatio-Motor and Phoneme Sequences. Journal of Cognitive Neuroscience 13:3, 370-388. [Abstract] [PDF] [PDF Plus]

35. Elizabeth Bates, Antonella Devescovi, Beverly Wulfeck. 2001. PSYCHOLINGUISTICS: A Cross-Language Perspective. Annual Review of Psychology 52:1, 369-396. [CrossRef]

36. Radek Ptak, Klemens Gutbrod, Walter Perrig, Armin Schnider. 2001. Probabilistic contingency learning with limbic or prefrontal damage. Behavioral Neuroscience 115:5, 993-1001. [CrossRef]

37. Elizabeth A. Kensinger, Michael T. Ullman, Suzanne Corkin. 2001. Bilateral medial temporal lobe damage does not affect lexical or grammatical processing: Evidence from amnesic patient H.M. Hippocampus 11:4, 347-360. [CrossRef]

38. Matti Laine, Riitta Salmelin, Päivi Helenius, Reijo Marttila. 2000. Brain Activation During Reading in Deep Dyslexia: An MEG StudyBrain Activation During Reading in Deep Dyslexia: An MEG Study. Journal of Cognitive Neuroscience 12:4, 622-634. [Abstract] [PDF] [PDF Plus]

39. Matthew D. Lieberman. 2000. Intuition: A social cognitive neuroscience approach. Psychological Bulletin 126:1, 109-137. [CrossRef] 
40. Nicholas Schiff, Urs Ribary, Fred Plum, Rodolfo Llinás . 1999. Words without MindWords without Mind. Journal of Cognitive Neuroscience 11:6, 650-656. [Abstract] [PDF] [PDF Plus] 